\title{
Providing evidence on the ongoing health care workers' mask debate
}

\author{
Dimitrios Tsilingiris $^{1} \cdot$ Margarita Papatheodoridi $^{2} \cdot$ Chris J. Kapelios ${ }^{3,4}(\mathbb{C}$
}

Received: 10 April 2020 / Accepted: 18 May 2020 / Published online: 29 May 2020

(c) Società Italiana di Medicina Interna (SIMI) 2020

\begin{abstract}
The scarcity of facemasks, particularly N95 respirators, combined with the lack of solid data to address the suitability of each mask type for adequate health care worker $(\mathrm{HCW})$ protection have caused turmoil among $\mathrm{HCW}$. Current recommendations suggest mask usage solely during HCW contact with Covid-19 patients, namely plain medical mask for low-risk contacts and N95 for aerosol generating procedures. The distinction regarding the escalation of mask complexity depending on contact type is nevertheless based on plausible theoretical assumptions rather than hard evidence of a clear benefit. Conversely, we suggest that at least a plain mask should be used during all HCWs' contacts in healthcare facilities which constitute a highly probable but often overlooked means of SARS-CoV-2 transmission among HCWs.
\end{abstract}

Keywords Covid-19 $\cdot$ Medical personnel $\cdot$ Medical mask $\cdot$ N95 $\cdot$ Respirator $\cdot$ SARS-CoV-2 $\cdot$ Pandemic

The exponential spread of the SARS-CoV-2 pandemic worldwide has brought about an unprecedented healthcare crisis, which is increasingly escalating today. One of the earliest and more worrisome aspects of this crisis is the shortage in personal protective equipment (PPE) for frontline health care workers (HCWs) [1].

As with other respiratory pathogens, including other human Coronaviruses (SARS-CoV, MERS-CoV) and Influenzae viruses, SARS-CoV-2 transmission primarily occurs through respiratory droplets emitted in various distances during coughing or sneezing of symptomatic infected individuals [2]. An open debate still exists regarding the potential of airborne viral shedding (implicating viral presence in droplet nuclei $<5 \mu \mathrm{m}$ in diameter that might remain, pending environmental conditions, aloft for

Chris J. Kapelios

chriskapel@hotmail.com; c.kapelios@1se.ac.uk

1 First Department of Propaedeutic Internal Medicine, Laiko General Hospital, National and Kapodistrian University of Athens, Athens, Greece

2 Institute of Liver and Digestive Health, School of Life and Medical Sciences, Royal Free Hospital, University College London, London, UK

3 Cardiology Department, Laiko General Hospital, 17 Agiou Thoma Street, 11527 Athens, Greece

4 Department of Health Policy, The London School of Economics and Political Science, London, UK several hours [3]). In a recent study, van Doremalen et al. [4] have shown that SARS-Cov-2 remains viable in an aerosol artificially generated by a collision nebulizer, with a half-life of approximately $1 \mathrm{~h}$. Nevertheless, it should be noted that this result was obtained under extremely idealized and unrealistic experimental conditions, not likely to be encountered by HCWs in real-world circumstances, and thus cannot be taken as definitive proof of airborne capacity of the SARS-COV-2 viral particle [5, 6]. In clinical settings, contamination of the environmental air around patients has been disputed among reports [7-9]. Overall, airborne transmission has been deemed as an unlikely major contributor to SARS-Cov-2 transmission [2,10], although it could play an important role during procedures that generate small droplets (aerosol-generating medical procedures, AGMPs) by HCWs [11]. Besides, the virus may be also detected in fomites, in blood and stool of patients, but related transmission modes have not yet been identified [2]. In any case, close contact between individuals seems to be paramount to viral transmission [12]. Accumulating data indicate that HCWs represent a significant proportion of total SARSCoV-2 cases, ranging between 9 and 29\% in different series [13-15]. Voices for the urgent need to protect HCWs to keep healthcare systems up and running throughout the pandemic are increasingly raised [16]. Use of barrier methods represent an essential step in this process.

Medical masks were initially designed to prevent the spread of infection from wearers to others but are now 
commonly used to protect the wearer too. Conversely, respirators, also referred to as high-filtration N95 masks, are fitted devices designed to protect the wearer from respiratory infections and are regulated by filtration capacity [17]. Recently witnessed shortage in respirators prompted the Centers for Disease Control and Prevention (CDC) to issue guidance on how respirators designed for single use may be reused and how medical masks can be used instead of respirators. Downgrading of recommended mask type from a respirator to a simple medical mask has also been implemented in the United Kingdom, causing turmoil among healthcare personnel [18]. But is this frenzy about HCWs' masks justified?

To date, it is assumed that plain surgical masks suffice for prevention of viral transmission from respiratory droplets, while N95 respirators provide additional protection from airborne transmission via aerosols [17]. Nonetheless, the differences in the effectiveness of face masks types in preventing SARS-CoV-2 are not clarified. Evidence from studies addressing protection from other respiratory viral pathogens, which are transmitted with a similar way to SARS-CoV-2, justifies either the use of medical masks or N95 respirators as substantially more effective than wearing neither in preventing viral transmission. A meta-analysis of observational studies performed during the 2002-2004 SARS outbreak concluded that there is consistent evidence to support the use of both simple medical masks (OR 0.32, 95\% CI 0.26-0.39 from seven studies, four among HCWs) and N95 respirators (OR 0.17, 95\% CI 0.07-0.43 from three studies among HCWs) [19]. The most recent evidence comes from a study from Hong-Kong showing that plain surgical masks effectively reduced the aerosol shedding of coronaviruses other than SARS-COV-2 in children and adults with respiratory infection [20].

A number of randomized controlled trials (RCTs) has also addressed this issue in healthcare settings. Loeb et al. conducted a randomized trial during the winter season of 2008-2009, comparing N95 to plain masks for prevention of influenza among 446 nurses in 8 medical centers in Ontario, Canada. There was no difference between the interventions regarding the probability of laboratoryconfirmed influenza, other viral infection or febrile influenza-like illness (ILI), and a pre-specified non-inferiority criterion between mask types was met [21]. Furthermore, in a cluster randomized trial, McIntyre et al. compared the efficacy of simple medical masks with fit- and nonfit-tested N95 for the prevention of viral illness during a single winter season among 1441 HCWs. After 4 weeks of intervention and an additional observatory week, N95 were reported to be more effective than simple masks for prevention of clinical respiratory illness (CLI, broadly defined as two respiratory or one respiratory and one systemic symptom) but not of ILI or laboratory proven influenza or other viral infection [22]. In another trial of identical design by the same investigators, an additional arm of intermittent N95 usage (when performing AGMPs or barrier nursing) was included; results showed a scaled increase of the probability of CLI for constant N95, intermittent N95 and plain mask usage, but no difference regarding proven viral infection, proven influenza infection or ILI [23]. Nonetheless, essential concern arises regarding the methodology of the latter two studies, as significant differences in baseline characteristics between the study groups indicate imperfections in the randomization procedure and probable contribution of confounders-recognized and not-to the reported results. In the largest and most recent cluster randomized trial among seven healthcare systems in the US. Radonovic et al. compared the efficacy of the two mask types among HCWs working in outpatient settings over four consecutive viral respiratory seasons. There were no ascertained differences regarding the primary outcome of laboratory-confirmed influenza or the secondary outcomes of proven or CLI and ILI [24].

As regards barrier measure application, compliance constitutes a key aspect that should be taken into account. Data from more than a decade ago show that adherence to mask wearing is associated with the prevention of respiratory viral illness among contacts in households [25]. More recently, this year, an early report from a hospital in Wuhan retrospectively examining risk factors associated with SARS-Cov-2 infection among $\mathrm{HCW}$ s revealed a protective role of contact history with confirmed or suspected SARS-Cov-2 patients, thus implying the considerable role of meticulous conformity to protective measures [26]. Due to the inherent features of their application, compliance issues would be expected to be more relevant in the case of N95 respirators. Sustained usage of N95 is associated with a gradual increase of blood $\mathrm{CO}_{2}$ content and perceived exertion, shortness of breath, headache and lightheadedness. Furthermore, frequent respirator adjustments and touching on or under the respirator have also been noted, probably hampering the functional integrity of the respirator as a barrier [27]. In the abovementioned RCTs adherence to study measures was either not assessed [21], found to be similar between intervention arms [22, 24], or shown to be lower among constant N95 than plain mask users and highest in intermittent $\mathrm{N} 95$ usage arm $(57 \%$ vs. $66 \%$ vs. $82 \% p<0.001)$ with a reverse trend for reported discomfort with mask usage among participants $(p<0.001)$ [23]. However, unavoidable differences between clinical trial settings and clinical reality cannot be overlooked. It is likely that under stringent working conditions over time the overall greater discomfort associated with sustained N95 usage in comparison with simple medical masks would add to HCWs' fatigue, hindering both their working capacity and adherence to mask usage and thus endangering patients and HCWs [28]. 
The lack of demonstrated benefit regarding the use of fitted N95 respirators appears at first glance counterintuitive, mainly due to the substantial inevitable leakage around the edge of loose-fitting plain surgical masks. However, this non-superiority of the N95 respirators represents an intriguing finding that may indicate gaps in the perceived model of viral transmission or may be a consequence of reduced compliance among N95 users, that leads to poorer net barrier function over time. Undoubtedly, it also highlights the capital importance of contact transmission (hands on face, mouth or nose) for viral respiratory pathogens, since both mask types apparently deter face touching among wearers in a similar way [17].

Overall, there is enough available evidence derived from reports earlier than the Covid-19 era to support the universal usage of medical masks as an inseparable component of personal protective equipment (PPE) among HCWs. On the other hand, there is limited data to advocate in favor of the generalized use in clinical routine of N95 respirators compared to plain masks, as they are more expensive and uncomfortable in long-term use [19], and possibly less readily available in adequate quantities during the early stages of an epidemic surge. Extrapolating this evidence to form recommendations for the current pandemic warrants extreme caution. Unavoidably, based on theoretical plausibility assumptions rather than hard evidence, World Health Organization (WHO) recommends the usage of N95 solely for HCWs during AGMPs and that of simple masks for other close contacts with suspected or confirmed SARS-COV-2 patients [29]. Notably, however, WHO does not recommend systematic use of a medical mask by HCWs during other activities within healthcare facilities, outside the treatment of Covid-19 diagnosed or suspected patients. This is a recommendation that we strenuously advocate against.

There is little data suggesting that contact with infected patients itself may not be the most significant contributor for in-hospital viral acquisition by HCW. Accordingly, unprotected or suboptimally protected close contacts (AGMPs inclusive) of HCWs with unidentified hospitalized cases of SARS-COV-2 did not result in illness or viral acquisition in two published reports from Hong-Kong (11 and 7 incidents $[8,10])$ and one from Singapore (41 incidents [30]). On the other hand, data from previous epidemics indicate that transmission between HCWs may be the predominant mechanism of their occupational infection [31]. Considerable aerosol emission occurs during the vocalization process and a wide interindividual variability characterizes the magnitude of this phenomenon, so that some individuals (or "super emitters") emit an unusually large number of droplets for a given vocalization compared to their peers [32]. Additionally, recent observations have underlined that the size-based, ad hoc distinction between droplets and aerosols (based on a droplet diameter greater or lesser than $5 \mu \mathrm{m}$ ) becomes less relevant when considering highly turbulent expiratory flows such as those that occur during coughing or sneezing. In the warm and humid local environment of a highly turbulent cloud exhaled during a cough or sneeze, droplets with a continuum of diameters may evade evaporation and hence remain airborne for a longer time period and in larger distances from the emitter. That is in stark contrast to the classical conception of isolated droplet behavior that occurs during normal exhalation, upon which the dichotomous distinction between droplets and aerosols is based and which primarily drives the rationale for the circumstances in which mask usage is considered necessary or not [33]. Collectively, the aforementioned observations signify that acceptably safe interactions between HCWs and other individuals require use of basic barrier protective measures in all potentially crowded and stressful in-hospital settings.

Based on the above, and considering the transmission risk that asymptomatic HCWs represent for their colleagues and patients, and the urgent need to keep HCWs as safe as possible to preserve sustainable healthcare system functionality throughout the pandemic, we strongly recommend that HCWs wear a medical mask during all their interactions within healthcare facilities. The demonstration of the benefits of plain mask usage regarding the efferent aerosol spreading of non-SARS-COV-2 coronaviruses further supports this notion [20], since this feature could theoretically hinder viral transmission from HCWs with mild or no symptoms to colleagues and patients. Nevertheless, theoretical benefits and surrogates of efficacy aside, every suchlike preventive strategy ought to eventually be evaluated through its clinical effectiveness [17]. In this context, it is noteworthy that a similar approach implemented early in the course of the epidemic in Hong-Kong including constant plain mask use by HCWs in in-hospital facilities with no contact with patients resulted in null transmission rates among health personnel over a period of 42 days [8]. Other measures of reducing exposure of HCWs to SARS-CoV-2 infection should also be considered and implemented where possible. These include but are not limited to the promotion of hand hygiene and environmental decontamination, assignment of dedicated healthcare staff, hospitals or wards within hospitals for Covid-19 patients, shiftwork of HCWs with minimization of physical interaction of different shift members, shutdown of all hospital facilities (cafeterias, dining rooms, gyms, etc.) that might affect unnecessary interaction between HCWs, and decrease of the frequency of high-risk interventions of unknown or limited efficacy in suspected or known Covid-19 patients.

In conclusion, it is likely that in the setting of the acute course of a pandemic much like the current, a certain degree of shortage will emerge for medical masks but even more so for N95. To force practices of debatable safety in the face of equipment scarcity, such as reuse of respirators, the usage 
of each mask type should be scaled for each medical task, as appropriate, based on the best available evidence. Therefore, we advocate that compliant use of a medical mask from all HCWs during their presence in healthcare facilities combined with other known measures of personal hygiene are expected to impact the control of the SARS-CoV-2 spread within healthcare personnel in the most meaningful and sizeable manner.

\section{Code availability}

Not applicable.

Author contributions All authors considerably contributed to the conception and writing of this manuscript.

Funding Not applicable.

Data availability Not applicable.

\section{Compliance with ethical standards}

Conflict of interest The author(s) declared that they have no conflict of interest.

Ethics approval Not applicable.

Consent to participate Not applicable.

Consent for publication All authors have provided consent for the publication of this manuscript.

\section{References}

1. Ranney ML, Griffeth V, Jha AK (2020) Critical supply shortages - the need for ventilators and personal protective equipment during the Covid-19 pandemic. New Eng J Med 382(18):e41. https://doi.org/10.1056/NEJMp2006141

2. OAfHPaPPh (2020) COVID-19-What we know so far about... routes of transmission. Queenss Printer for Ontario, Toronto

3. Xie X, Li Y, Chwang AT, Ho PL, Seto WH (2007) How far droplets can move in indoor environments-revisiting the Wells evaporation-falling curve. Indoor Air 17(3):211-225. https://doi. org/10.1111/j.1600-0668.2007.00469.x

4. van Doremalen N, Bushmaker T, Morris DH, Holbrook MG, Gamble A, Williamson BN, Tamin A, Harcourt JL, Thornburg NJ, Gerber SI, Lloyd-Smith JO, de Wit E, Munster VJ (2020) Aerosol and surface stability of SARS-CoV-2 as compared with SARS-CoV-1. New Eng J Med 382(16):1564-1567. https://doi. org/10.1056/NEJMc2004973

5. Lesho E, Laguio-Vila M, Walsh E (2020) Stability and viability of SARS-CoV-2. New Eng J Med. https://doi.org/10.1056/NEJMc 2007942

6. Schwartz KL, Kim J, Garber G (2020) Stability and viability of SARS-CoV-2. New Eng J Med. https://doi.org/10.1056/NEJMc 2007942
7. Guo ZD, Wang ZY, Zhang SF, Li X, Li L, Li C, Cui Y, Fu RB, Dong YZ, Chi XY, Zhang MY, Liu K, Cao C, Liu B, Zhang K, Gao YW, Lu B, Chen W (2020) Aerosol and surface distribution of severe acute respiratory syndrome coronavirus 2 in hospital wards, Wuhan, China, 2020. Emerg Infect Dise. https://doi. org/10.3201/eid2607.200885

8. Cheng VCC, Wong SC, Chen JHK, Yip CCY, Chuang VWM, Tsang OTY, Sridhar S, Chan JFW, Ho PL, Yuen KY (2020) Escalating infection control response to the rapidly evolving epidemiology of the coronavirus disease 2019 (COVID-19) due to SARS-CoV-2 in Hong Kong. Infect Control Hosp Epidemiol. https://doi.org/10.1017/ice.2020.58

9. Ong SWX, Tan YK, Chia PY, Lee TH, Ng OT, Wong MSY, Marimuthu K (2020) Air, surface environmental, and personal protective equipment contamination by severe acute respiratory syndrome coronavirus 2 (SARS-CoV-2) from a symptomatic patient. JAMA. https://doi.org/10.1001/jama.2020.3227

10. Wong SC, Kwong RT, Wu TC, Chan JWM, Chu MY, Lee SY, Wong HY, Lung DC (2020) Risk of nosocomial transmission of coronavirus disease 2019: an experience in a general ward setting in Hong Kong. J Hosp Infect. https://doi.org/10.1016/j. jhin.2020.03.036

11. World Health Organization (2020) Modes of transmission of virus causing COVID-19: implications for IPC precaution recommendations. Retrieved from https://www.who.int/newsroom/commentaries/detail/modes-of-transmission-of-virus -causing-covid-19-implications-for-ipc-precaution-recommenda tions

12. Chan JF, Yuan S, Kok KH, To KK, Chu H, Yang J, Xing F, Liu J, Yip CC, Poon RW, Tsoi HW, Lo SK, Chan KH, Poon VK, Chan WM, Ip JD, Cai JP, Cheng VC, Chen H, Hui CK, Yuen KY (2020) A familial cluster of pneumonia associated with the 2019 novel coronavirus indicating person-to-person transmission: a study of a family cluster. Lancet 395(10223):514-523. https:// doi.org/10.1016/S0140-6736(20)30154-9

13. Livingston E, Bucher K (2020) Coronavirus disease 2019 (COVID-19) in Italy. JAMA. https://doi.org/10.1001/ jama.2020.4344

14. Wang D, Hu B, Hu C, Zhu F, Liu X, Zhang J, Wang B, Xiang H, Cheng Z, Xiong Y, Zhao Y, Li Y, Wang X, Peng Z (2020) Clinical characteristics of 138 hospitalized patients with 2019 novel coronavirus-infected pneumonia in Wuhan, China. JAMA. https ://doi.org/10.1001/jama.2020.1585

15. Department of Health (2020): An analysis of the 1,383 cases of COVID-19 in Ireland (as of Tuesday 24 March 2020). Retrieved from https://www.gov.ie/en/publication/173d8c-an-analysis-ofthe-1383vcases-of-covid-19-in-ireland-as-of-tuesday-2/

16. The L (2020) COVID-19: protecting health-care workers. Lancet 395(10228):922. https://doi.org/10.1016/S0140-6736(20)30644-9

17. MacIntyre CR, Chughtai AA (2015) Facemasks for the prevention of infection in healthcare and community settings. BMJ 350:h694. https://doi.org/10.1136/bmj.h694

18. Campbell D, Busby M (2020) 'Not fit for purpose': UK medics condemn Covid-19 protection. Retrieved from https://www.thegu ardian.com/society/2020/mar/16/not-fit-for-purpose-uk-medic s-condemn-covid-19-protection

19. Jefferson T, Del Mar CB, Dooley L, Ferroni E, Al-Ansary LA, Bawazeer GA, van Driel ML, Nair S, Jones MA, Thorning S, Conly JM (2011) Physical interventions to interrupt or reduce the spread of respiratory viruses. Cochrane Database Syst Rev. https ://doi.org/10.1002/14651858.CD006207.pub4

20. Leung NHL, Chu DKW, Shiu EYC, Chan K-H, McDevitt JJ, Hau BJP, Yen H-L, Li Y, Ip DKM, Peiris JSM, Seto W-H, Leung GM, Milton DK, Cowling BJ (2020) Respiratory virus shedding in exhaled breath and efficacy of face masks. Nat Med. https://doi. org/10.1038/s41591-020-0843-2 
21. Loeb M, Dafoe N, Mahony J, John M, Sarabia A, Glavin V, Webby R, Smieja M, Earn DJ, Chong S, Webb A, Walter SD (2009) Surgical mask vs N95 respirator for preventing influenza among health care workers: a randomized trial. JAMA 302(17):18651871. https://doi.org/10.1001/jama.2009.1466

22. MacIntyre CR, Wang Q, Cauchemez S, Seale H, Dwyer DE, Yang P, Shi W, Gao Z, Pang X, Zhang Y, Wang X, Duan W, Rahman B, Ferguson N (2011) A cluster randomized clinical trial comparing fit-tested and non-fit-tested N95 respirators to medical masks to prevent respiratory virus infection in health care workers. Influenza Other Respir Viruses 5(3):170-179. https://doi.org/10.111 $1 / \mathrm{j} .1750-2659.2011 .00198 . x$

23. MacIntyre CR, Wang Q, Seale H, Yang P, Shi W, Gao Z, Rahman B, Zhang Y, Wang X, Newall AT, Heywood A, Dwyer DE (2013) A randomized clinical trial of three options for N95 respirators and medical masks in health workers. Am J Respir Crit Care Med 187(9):960-966. https://doi.org/10.1164/rccm.201207-1164OC

24. Radonovich LJ Jr, Simberkoff MS, Bessesen MT, Brown AC, Cummings DAT, Gaydos CA, Los JG, Krosche AE, Gibert CL, Gorse GJ, Nyquist AC, Reich NG, Rodriguez-Barradas MC, Price CS, Perl TM, Pi R (2019) N95 respirators vs medical masks for preventing influenza among health care personnel: a randomized clinical trial. JAMA 322(9):824-833. https://doi.org/10.1001/ jama.2019.11645

25. MacIntyre CR, Cauchemez S, Dwyer DE, Seale H, Cheung P, Browne G, Fasher M, Wood J, Gao Z, Booy R, Ferguson N (2009) Face mask use and control of respiratory virus transmission in households. Emerg Infect Dis 15(2):233-241. https://doi. org/10.3201/eid1502.081167

26. Ran L, Chen X, Wang Y, Wu W, Zhang L, Tan X (2020) Risk factors of healthcare workers with corona virus disease 2019: a retrospective cohort study in a designated hospital of Wuhan in China. Clin Infect Dis. https://doi.org/10.1093/cid/ciaa287

27. Rebmann T, Carrico R, Wang J (2013) Physiologic and other effects and compliance with long-term respirator use among medical intensive care unit nurses. Am J Infect Control 41(12):1218-1223. https://doi.org/10.1016/j.ajic.2013.02.017

28. Li Y, Tokura H, Guo YP, Wong AS, Wong T, Chung J, Newton E (2005) Effects of wearing N95 and surgical facemasks on heart rate, thermal stress and subjective sensations. Int Arch Occup Environ Health 78(6):501-509. https://doi.org/10.1007/s0042 0-004-0584-4

29. World Health Organization (2020) Rational use of personal protective equipment for coronavirus disease (COVID-19) and considerations during severe shortages. Retrieved from https://www. who.int/publications-detail/rational-use-of-personal-protective -equipment-for-coronavirus-disease-(covid-19)-and-considerat ions-during-severe-shortages

30. Ng K, Poon BH, Kiat Puar TH, Shan Quah JL, Loh WJ, Wong YJ, Tan TY, Raghuram J (2020) COVID-19 and the risk to health care workers: a case report. Ann Intern Med. https://doi.org/10.7326/ L20-0175

31. Ang B, Poh BF, Win MK, Chow A (2010) Surgical masks for protection of health care personnel against pandemic novel swine-origin influenza A (H1N1)-2009: results from an observational study. Clin Infect Dis 50(7):1011-1014. https://doi.org/10.1086/651159

32. Asadi S, Wexler AS, Cappa CD, Barreda S, Bouvier NM, Ristenpart WD (2019) Aerosol emission and superemission during human speech increase with voice loudness. Sci Rep 9(1):2348. https://doi.org/10.1038/s41598-019-38808-z

33. Bourouiba L (2020) Turbulent gas clouds and respiratory pathogen emissions: potential implications for reducing transmission of COVID-19. JAMA. https://doi.org/10.1001/jama.2020.4756

Publisher's Note Springer Nature remains neutral with regard to jurisdictional claims in published maps and institutional affiliations. 